\title{
Hydrological Response and Ecological Flow Optimization in Water Diversion Area of Inter-Basin Water Diversion Project
}

Tao Bai ( $\sim$ baitao@xaut.edu.cn )

State Key Laboratory of Eco-Hydraulics in Northwest Arid Region https://orcid.org/0000-0003-14478497

xian-ge sun

Xi'an University of Technology

Jian Wei

Xi'an university of technology

\section{Lianzhou Wu}

Northwest A\&F University

\section{Research Article}

Keywords: Hydrological response, Ecological flow, Hydrologic indicators, Reservoir operation, Hanjiang-toWeihe River inter-basin water transfer project

Posted Date: January 27th, 2022

DOI: https://doi.org/10.21203/rs.3.rs-1260976/v1

License: (c) (1) This work is licensed under a Creative Commons Attribution 4.0 International License. Read Full License 


\title{
Hydrological response and ecological flow optimization in
}

\section{water diversion area of inter-basin water diversion project}

\author{
Tao Bai ${ }^{1}$, Xian-ge Sun ${ }^{1}$, Jian $\mathrm{Wei}^{2}$, Lianzhou $\mathrm{Wu}^{3}$ \\ (1. State Key Laboratory of Eco-hydraulics in Northwest Arid Region of China, Xi'an University of Technology, Jinhua Road 5, Xi'an, Shanxi 710048, \\ China; 2. China Northwest Water Conservancy \& Hydropower Engineering Consulting Co. Ltd., Shanxi 710100, China;3.
}

Key Laboratory for Agricultural Soil and Water Engineering in Arid Area of Ministry of Education, Northwest A\&F University, Yangling, Shaanxi 712

100 , China)

\begin{abstract}
To quantify the impact of inter-basin water transfer project on hydrological and ecological environment of downstream river, taking Hanjiang-to-Weihe inter-basin water transfer project in the initial operation period for example, hydrological response and ecological flow optimization in water diversion area after water transfer are discussed in this paper. Firstly, Multi-year reservoir operation model of "Sanhekou" is established by MIKE BASIN. Hydrological indicators system construct by Indicators of Hydrologic Alteration (IHA) and Range of Variability Approach (RVA). Then, verify change degree of hydrologic response before and after the reservoir is built. Moreover, 33
\end{abstract} hydrological indicators in IHA consist of five groups to quantitatively evaluate the change degree of hydrological indicators. Finally, seven schemes of different ecological flow processes are set, and the optimal scheme is recommended by AHP. Considering ecological flow management, propose improvement measures from both engineering and non-engineering aspects. The results show that: (1) MIKE BASIN simulation results and design results have a high degree of fit, which verifies rationality of the model; (2) The overall hydrological change of the river is $72.91 \%$, and hydrological response of the river lead to highly change; (3) Scheme 6 reduces overall change degree of hydrology to $(56.63 \%)$ middle change under premise of less impact on economic benefits, 
recommended Scheme 6 as the optimal scheme. The research results not only provide important guidance and reference for maintenance and protection of ecological functions of rivers, but also the actual operation of reservoirs.

Keywords: Hydrological response; Ecological flow; Hydrologic indicators; Reservoir operation; Hanjiang-to-Weihe River inter-basin water transfer project

\section{Introduction}

The large-scale development of urbanization and industrialization aggravates the contradiction of water shortage, and a series of problems followed seriously threatens sustainable development of regional economy and virtuous circle of ecological environment. Therefore, water conservancy projects in upper rivers by human beings are built to utilize water resources so that can be reduced the economic loss caused by water shortage. On one hand, reservoir built effectively alleviates the crisis of water shortage, improves utilization efficiency of water resources, and brings remarkable benefits. On the other hand, ecological flow in different season cannot be safeguarded and biodiversity in river basin are seriously damaged after reservoirs built (Han, 2014; Cui et al., 2004). According to incomplete statistics by scholars, more than $20 \%$ species fish in the river have disappeared or endangered in the world caused by human damming event (Mccully, 2001). The main reason can be attributed to disconnection of the river and variable hydrological conditions by dam, which reduced aquatic species and simplified biological population structure immediately (Bernard et al., 2005).

Exploring impact of dam built and operation on river channel ecology is a hot issue studied abroad. By evaluating the indicators in IHA, they found that hydrological indicators of river channel ecology 
have generally changed more than middle changes. For instance, trend of annual extreme flow change (Costigan, 2012; Ashraf et al., 2016), natural runoff pattern changes by monthly average flow rate (Al-Farajet et al., 2014), change of connectivity and related ecological service functions caused by high and low flow pulses and seasonal law of flow in downstream (Ibraim et al., 2015). Apart from this, there are other indicators beyond scope of IHA indicators, for example, deterioration of water quality, disconnection of river, and decrease of riparian vegetation outside rivers, phytoplankton and fish community biodiversity in rivers (Natália et al., 2018; Oscar et al., 2013; Swapan et al., 2019).

Domestic scholars have done a lot of research on impact of water conservancy projects in different basins to explore influence on river ecology. The results demonstrate that, built and operation of water conservancy projects will have adverse effects on river ecology. For instance, flood frequencies are drop-down in flood season, but frequencies and lasted time of medium-small flow pulse are significantly increase in non-flood season, which all caused by Taizi reservoir operation (Zhang et al., 2012). River downstream water quality deteriorates, soil erodes seriously, and sediment transport reduces after Songhuajiang water conservancy project operation. (Yang et al., 2013). It produces same problem on downstream river bed by built of Feilaixia reservoir, also include flood speed increases, and flood peak appears earlier. (Huang et al., 2014). Similarly, ecological flow in Jinjiang river decreased and drying days increased in downstream channel after Jinjiang reservoir built (Chen et al., 2015). Hydrological situation in Three Outlets of Jingiiang river changed after Three Gorges Project built and operated, such as decreased outflow downstream, shorted flood season and decreased day maximum flow (Gao et al., 2020). Eco-hydrological conditions changed by Three Gorges Dam, in turn cause spawning and reproduction of four common 
fish species be influenced. (Guo et al., 2018). Downstream rivers increase discharge in the dry season but decrease in wet and normal seasons due to impoundment of Danjiangkou dam. Climate changed rainfall, monthly median, and annual maximum flows, and lead to low-flow pulses increase. Touched by backwater, monthly median flow and annual minimum flow on Huangjiagang hydrological station is increase, which located downstream of Danjiangkou reservoir (Ban et al., 2020).

Reservoirs need to discharge ecological water that meets requirements within certain time and area, to reduce or alleviate negative ecological environment of the river by water conservancy projects constructed and operating. However, without considering with hydrological response of natural runoff and ecological requirements, most reservoirs operation schemes only met minimum ecologically flow demand. Thus, most scholars at home and abroad focused on ecological and environmental effects caused by reservoir built to draw up reasonable ecological flow process, which can be surely maintained river ecological health.

However, owing to lack of relevant scientific basis and technical support, ecological base flow requirement (as a constant parameter) clearly put forward in Hanjiang-to-Weihe River diversion project, channel health of the downstream and security of the river basin ecosystem cannot maintain by unreasonable ecological operation only with ecological base flow. At present, Sanhekou Reservoir of Inter-basin water diversion project from Hanjiang-to-Weihe River has begun to store water and will achieve preliminary operation by 2020. Sanhekou Reservoir is urgent to simulate river hydrological response under design and operation plan of reservoir and optimize ecological flow to alleviate negative effects of reservoir operation, provide theoretical and technical support for maintaining and ensuring health of river ecological functions. Therefore, studying hydrological 
response and ecological flow optimization of rivers in water transfer area of the inter-basin water transfer project has important theoretical significance and application value.

\section{Study area and data}

\subsection{Study area}

As important basic engineering to alleviate shortage of water resources and improve utilization efficiency of water resources in Shaanxi Province, Hanjiang-to-Weihe Inter-basin water diversion project not only produces great significance to promote economic and social development but also has a far-reaching impact on ecological environment protection of province. Hanjiang-to-Weihe Inter-basin water diversion project is the first time that attempts to cross a mountain tunnel from bottom of the world. The tunnel across Qinling Mountains is $98.3 \mathrm{~km}$ long, and maximum buried depth reaches 2012 meters. Tunnel length, buried depth, and built difficulty rank first in the world. At the same time, due to complex geological conditions, rock burst, water gushing, high temperature and humidity, high abrasion of hard rock, and heavy deformation of soft rock often occur during built, which greatly increases built difficulty. According to project situation, to make full use of economic benefits of project, Sanhekou Reservoir operates independently in early stage of Hanjiang-to-Weihe Inter-basin water diversion project. The main task of reservoir is water supply, followed by power generation. The hydropower station adopts power generation methods of “determining electricity by water", mainly using water supply, ecological water, and head formed between dam and tail water level of hydropower station. At the same time, the reservoir also carries out task of ecological water intake downstream. Taking Ziwu River basin, a tributary of Hanjiang River, as the study area, this paper analyzes influence of initial operation of project on hydrological 
process in Ziwu river basin. Ziwu River is between $\mathrm{N} 33^{\circ} 18^{\prime} \sim \mathrm{N} 33^{\circ} 44^{\prime}$ and $\mathrm{E} 107^{\circ} 51^{\prime} \sim \mathrm{E} 108^{\circ} 30^{\prime}$ and belongs to chief tributary on north bank of Hanjiang river (Fig.1). Ziwu River is under jurisdiction of Ningshan County and Foping County. It is about 160 kilometers long and covers an area of more than 3,000 square km. Ziwu River tributaries numerous, mainly including Wenshui River, Puhe river, Jiaoxi River. Reservoir dam site locates $2 \mathrm{~km}$ downstream from confluence of three tributaries.

\subsection{Study data}

Data required for this paper include reservoir power station data, runoff data, and water demand data. Reservoir power station data includes characteristic parameters of Sanhekou Water Control Project in Ziwu River Basin. Runoff data includes day measured flow process of Lianghekou hydrological station from 1964 to 2013, and some missing data are obtained by interpolation from Yangxian and neighboring hydrological stations. Flow process of day flow series at the dam site from 1964 to 2013 obtain by area comparison method, because there is no hydrological station at the dam site of Sanhekou Reservoir. Supply and demand situation of water resources in initial operation of water diversion project from Hanjiang-to-Wei river is relatively simple, mainly including water supply in receiving area and ecological water demand in downstream rivers. Wherein receiving area for industrial and living water, water demand is more stable, therefore, can be satisfied by equal-delivery. According to planning, ecological water demand of downstream rivers design $10 \%$ of annual average runoff, which is $2.71 \mathrm{~m}^{3} / \mathrm{s}$. The data are as follows in Table1(a)(b).

\section{Methodology}

\subsection{MIKE BASIN Model}


MIKE Basin is a mathematical simulation software developed by Danish Hydraulic Institute (DHI) for water resources distribution and water resources supply and demand balance affected by spatial and temporal factors on the basin scale. Based on existing digital basin elevation map (DEM), the model can automatically generate channels, construct river networks, and divide sub-basins by adding reservoir performance, river network tracking, scheduling rules, and water users. Simulation of water resources distribution in watershed using steady water balance equation. Among them, water balance is the core calculation program, and the calculation formulas of water balance in different scales and regions usually have different variants. For closing watersheds without inter-basin water transfer, the water balance formula is:

$$
P=E T+R+\Delta S
$$

In formula: $P$ represent rainfall in basin; $E T$ represent vertical evapotranspiration; $R$ represent sum of lateral surface water and groundwater outflows; $\Delta S$ represent sum of changes in soil water, surface water, and groundwater storage.

Compared with traditional reservoir optimal operation model, MIKE BASIN has following two advantages: (1) MIKE BASIN considers not only influence of time factors but also the influence of spatial factors, which is suitable for case studies on different time scales (years, months, days, hours, et al.) and spatial scales (basins, water users, nodes, rivers). (2) MIKE BASIN has powerful functions such as result display, data interaction, and portability.

In the built of actual model, appropriate modules and attributes should be selected according to characteristics of water requirement. Up to now, MIKE BASIN has been used to solve water resources allocation and reservoir operation cases in multiple basins (e.g., Li et al,2013; Chen et al,2009; Qi et al,2018; Meng et al,2014; Lu et al,2016; Jha et al.,2003; Hassaballah et al,2012). In 
this study, MIKE BASIN scheduling model of Ziwu River basin establishes based on MIKE software. Firstly, obtain DEM digital basin map, and design specific parameters of period length, step length, iteration number, and flow convergence standard set in software. DEM data loaded into MIKE BASIN model to describe river network, flow direction, river network tracking, and sub-basin division. Secondly, water resources zoning map is imported into MIKE BASIN interface, and basic attributes are edited. According to characteristics of the watershed, divided the watershed into three sub-basins, and the existing runoff series is directly loaded into the model through sequence file. Then add reservoir nodes and remote control points on the map, and edit reservoir properties, mainly including: reservoir capacity-water level-area table, reservoir regulating water level, characteristic water level table ( dead water level, reservoir dam top elevation, reservoir bottom elevation ), maximum and minimum flow table, water supply priority, minimum operating water level table, flood limit water level table, remote control point flow table, reduction rules ( water level, reduction rate ) table, spillway attribute table, etc. Among them, remote control point flow table is river ecological water demand process. Water users added into map. reservoir water supply as water supply method of Ziwu river basin and water supply connection between reservoir and water users are drawn on map. Water supply of reservoir conveys to Huangchigou regulating pool through Qinling water tunnel. Therefore, there is not required to set up water user backwater connection or set backwater ratio to 0 and edit water user water requirements file at the same time.

\subsection{Verification of MIKE BASIN Model}

Up to now, Sanhekou Reservoir has not been officially put into operation, according to initial reservoir operation process in design report, simulation results of MIKE BASIN model are as consistent as possible with the design process through multiple operation models, parameter 
adjustment and optimization, finally, the parameters of MIKE BASIN operation model of Sanhekou Reservoir are determined and selected. This paper collects measured runoff data from 1964 to 2014. Multi-time scale analysis of inflow runoff series in Sanhekou Reservoir carried out by wavelet analysis, and results show that middle periodic of measured runoff series is six years. The same trend of runoff variation in different periods does not affect simulation results. Simply verifying fitting degree between design value and simulation value, so this paper chooses data from 1964-1969. Therefore, measured runoff process from 1964 to 1969 selected to simulate results, water level change process, ecological water discharge process, and water supply process are compared between simulation and design reports of Sanhekou Reservoir, as shown in Fig.2 Fig.4.

It can be seen from Fig. 2 to Fig. 4 that changing trend of MIKE BASIN simulation results consists of design results. Model has well-simulated water resources change dynamics at initial stage of reservoir operation, further calculation shows that: annual average errors of water level process, ecological drainage, and water supply are $1.21 \%, 0.15 \%$, and $0.38 \%$ respectively. The results show that fitting relationship is in accord between simulation results and design results of MIKE BASIN model, and rationality of model satisfy and can be used for ecological effect evaluation calculation.

\subsection{Ecological effect evaluation method}

\subsubsection{IHA method}

Up to now, scholars at home and abroad have done lots of research on the change of hydrological situation by human activities and put forward a series of indicators to evaluate hydrological changes. On this basis, 33 hydrological change indicators (IHA, Indicators of Hydrologic Alteration) are summarized. The above indicators can be divided into five groups according to change rate, frequency, period, duration, and size of flow to evaluate changes in river hydrological situation 
before and after impact of human activities. At the same time, based on a large amount of field monitoring data, the response relationship between indicators and river ecosystems is summarized as shown in Table 2. (Richter et al., 1996). Hydrological change indicators affect structure and function of ecosystem, reflecting degree of change in ecological environment before and after activities.

\subsubsection{RVA Method}

To quantitatively calculate change degree of interference with each hydrological indicator in IHA, Range of Variability Approach (RVA) propose based on IHA (Richter et al., 1997). RVA has a high requirement for accuracy of runoff series, which generally requires more than 20 years of day runoff data, by calculating IHA indicators before reservoir built, sorting percentage of each indicators are divided into three intervals: $R 1=[0,25 \%], R 2=[25 \%, 75 \%]$ and $R 3=[75 \%, 100 \%], \mathrm{R} 2$ is also called RVA threshold as the interval to meet ecological needs. Comparing frequency of IHA flow indicators falling into RVA range before and after reservoir built, if most of flow indicators values fall within RVA threshold value after built of reservoir, it indicates that range of river hydrological regime change is acceptable. On the contrary, it shows that hydrological situation of river has changed greatly, indicating that built of the reservoir has a serious impact on ecological environment of river.

Richter proposed an assessment method to quantitatively calculate degree of hydrological change affected by hydrological indicators, defining degree of hydrological change as follows:

$$
\begin{gathered}
D_{i=}\left|\frac{N_{i}-N_{0}}{N_{0}}\right| \times 100 \% \\
N_{0}=r N_{T}
\end{gathered}
$$

Type: $D_{i}$ represents the degree of change of the $i$-th hydrological indicator; $N_{i}$ and $N_{0}$ said the years after built of reservoir and expected IHA indicators fell within threshold range of RVA; $r$ 
indicates proportion of years when IHA falls within threshold range of RVA before reservoir built; $N_{T}$ Indicates total number of years affected.

Richter also set an objective judgment standard for hydrological change degree of hydrological indicators, and standard stipulates that: $0 \leqslant D_{i}<33 \%$ represents that indicators has changed at a low level, $33 \% \leqslant D_{i}<67 \%$ represents that indicators has middle changed; $67 \leqslant D_{i}<100 \%$ represents that indicators has high changed.

Overall change degree of hydrological indicators $\left(D_{0}\right)$ the calculation formula is as follows:

$$
D_{0}=\sqrt{\frac{1}{3} \sum_{i=1}^{33} D_{i}^{2}}
$$

Definition: If $0 \leqslant D 0<33 \%$, changes in hydrological indicators are slight or unchanged: if $33 \leqslant D 0$ $<67 \%$ change degree of hydrological indicators belongs to middle change; if $67 \% \leqslant D 0<100 \%$ change degree of hydrological indicators belongs to high change.

\subsection{Ecological flow scheme setting}

Sanhekou Reservoir locates in middle valley of Ziwu River at the junction of Foping County and Ningshan County, Shaanxi Province. Runoff at dam site consists of three tributaries, namely Wenshui River, Puhe River, and Jiaoxi River, and slope confluence. After built of Sanhekou Reservoir, downstream discharge is directly affected by the reservoir regulation, and its flow sequence can reflect variation characteristics of flow below the dam site. At the same time, considering the current situation that the reservoir has not yet operation, this study takes the dam site as representative section to analyze Ziwu river downstream runoff variation law before and after reservoir built. The day runoff process at the dam site from 1964 to 2013 takes as runoff process before reservoir built. Using reservoir discharge process simulated by MIKE BASIN software as 
ecological flow process after reservoir built in the design scheme. The process of reservoir inflow and outflow is shown in Fig.5.

It can be seen in Fig. 5 that, maximum flow before reservoir built is $1532.30 \mathrm{~m}^{3} / \mathrm{s}$, and minimum flow is $0.47 \mathrm{~m}^{3} / \mathrm{s}$. After the reservoir built, maximum flow is $1516.45 \mathrm{~m}^{3} / \mathrm{s}$, and minimum flow is $2.71 \mathrm{~m}^{3} / \mathrm{s}$, which meets minimum ecological flow constraint. On the inter-annual scale, fluctuation of discharge after reservoir built is less than that before, mainly because multi-year regulation of reservoir capacity has played a part in storing abundant resources and replenishing dry resources. From the perspective of the year, the annual variation of the discharge is more than that before based on meeting ecological water demand, which is mainly characterized by small discharge in non-flood season and large discharge in flood season. The main reason is that reservoir should discharge flow according to ecological water demand in non-flood season to achieve a stable water supply process and ensure water supply satisfaction rate.

River ecological flow in current operating scheme is $10 \%\left(2.71 \mathrm{~m}^{3} / \mathrm{s}\right)$ of annual average flow. Results by IHA-RVA method are shown that high degree change happened on river by this scheme. Referring to previous studies on ecological flow of Ziwu River (Li et al, 2017; Chang et al, 2007), it can be found that the current ecological flow scheme has obvious defects and deficiencies as follow:

(1) The overall ecological flow is relatively small.

(2) Ecological flow does not reflect changes in different periods of the year.

(3) The ecological flow does not reflect the inter-annual abundance and dryness characteristics.

A large number of studies have shown that stability of river ecosystems and the conditions for survival and reproduction of species have different requirements for hydrological processes during the inter-year and different periods of the year. Therefore, when calculating ecological flow, the 
characteristics of river hydrological process should be fully reflected. At the same time, studies have shown that: different frequencies of average annual flow correspond to different river health standards, for example, $10 \%$ of average annual flow corresponds to flow degradation or barren conditions. (Xu et al., 2003).

Currently, ecological flow calculation methods are divided into habitat method, holistic method, hydraulic method, and hydrological method (Macdonald, 2004). In this paper, hydrological method is utilized to calculate ecological flow of rivers. At the same time, considering that runoff time scale of this study is day, the article uses the multi-year day flow data frequency ranking method to calculate (Yang et al., 2013). The calculation idea is frequency ranking of multi-year daily flow data, and different frequencies are selected in different periods.

To ensure ecological health and biological reproduction of rivers, the requirements of river flow are different at different stages of the year and between years. The design of ecological flow should fully reflect characteristics of inter-annual variation of river hydrological process and the demand of different stages in a year. Based on above analysis, this paper takes Scheme 1 as basic scheme, and sets up several ecological flow scheduling schemes, as shown in Table 3.

\section{Results and Discussions}

Collect the data of monthly average flow, annual extreme flow and occurrence time, high and low flow indicators, and change rate and frequency of flow conditions before and after reservoir built to calculate the overall change degree of the hydrological indicators. According to ecological flow Scheme 2 7, different day flow frequencies set by different annual variation and inter-annual 
variation characteristics are considered to calculate the guarantee rates of water supply, power generation, and ecological water in each scheme.

\subsection{River hydrological response analysis}

Variation degree of IHA indicators before and after reservoir built are calculated by RVA shown in Table 4.

Average annual flow in flood season is $54.81 \mathrm{~m}^{3} / \mathrm{s}$, and that in non-flood season is $12.10 \mathrm{~m}^{3} / \mathrm{s}$ before reservoir built; Average annual flow in flood season is $26.03 \mathrm{~m}^{3} / \mathrm{s}$, and that in non-flood season is $2.95 \mathrm{~m}^{3} / \mathrm{s}$ after the reservoir built.

Table 3 shows changes of each group of hydrological indicators:

(1) Monthly average flow decreases to varying degrees, mainly because the reservoir undertakes water supply task of 500 million $\mathrm{m}^{3}$ at initial stage of the project. In which monthly average flow in flood season (July October) middle changes occur, and monthly average flow in non-flood season (November June of the following year) a high degree of change occurs.

(2) Minimum flow on 1-day and 3-day increase compared with that before reservoir built, and minimum flow on 7, 30, and 90 days after reservoir built decrease compared with before reservoir built. Which indicates that effects of multi-year regulation and storage performance on minimum flow of Sanhekou Reservoir are improve and enhance on day time scale, but are limited on weekly, monthly and seasonal time scales. The basic flow indicators increased from 0.12 to 0.51 after reservoir built.

(3) Minimum flow and maximum flow occurred earlier than before reservoir built, and decreasing trend of maximum flow on different time scales does not vary. 
(4) Except for base flow, annual extreme flow and the time when extreme flow occurs all show middle and high changes. Frequency of low flow decreased but average duration of low flow increased from 15.49 days to 232.90 days after the reservoir built. Frequency of high flow decreases but the duration of high flow increases from 3.17 to 3.81 days after reservoir built.

(5) Average increase rate of flow increased from $19.73\left(\mathrm{~m}^{3} /(\mathrm{s} \cdot \mathrm{d})\right)$ to $73.95\left(\mathrm{~m}^{3}\right) /(\mathrm{s} \cdot \mathrm{d})$ after built of the reservoir; average flow reduction rate changed from $-9.38\left(\mathrm{~m}^{3} /(\mathrm{s} \cdot \mathrm{d})\right.$ to $28.46\left(\mathrm{~m}^{3} /(\mathrm{s} \cdot \mathrm{d})\right.$ after reservoir built. Annual flow reversal time decreased from 104.90 times to 13.45 times after reservoir built.

Basis on change degree of 33 IHA hydrological indicators to statistics indicators change distribution situation before and after reservoir built. Results can be seen from Fig.6(a)(b), among 33 IHA indicators, $14(42 \%)$ are high degree changed, 18 (55\%) are middle degree changed, and only 1 (3\%) is slight degree changed. According to formula, overall change degree of river hydrological regime after reservoir built is $72.91 \%$, which belongs to high degree change. Results show that scheduling based on design scheme operation, significant change of reservoir downstream river hydrology situation. Main reason is: Sanhekou Reservoir is a water conservancy project with the largest built scale and wide influence range on Ziwu River. The reservoir is a multi-year regulating reservoir, mainly to water supply, which affects discharge flow process in a great extent.

\subsection{Change of hydrological indicators under each scheme}

\subsubsection{Changes in hydrological indicators}

Taking day runoff data from 1964 to 2013 as day runoff series before reservoir built. Taking MIKE BASIN simulated discharge process as day runoff series after reservoir built. The changes of IHA hydrological indicators in Scheme 2 Scheme 7 are calculated, as shown in Fig.7. 
(1) Monthly average flow change

Fig.7 shows monthly average traffic changes for different schemes.

(2) Annual extreme flow

Minimum flow process and maximum flow process of different schemes are presented in Fig.8 and Fig.9. With increase in time scale, minimum flow process shows an increasing trend, and maximum flow process shows a decreasing trend, which have same trend as before reservoir built. Except Scheme 2, minimum 1 day flow and minimum 3-day flow of all schemes are better than the natural runoff process.

It shows that extremely low flow can be promoted and improved by reservoir operation, but limited influences in the large time scale. The differences between minimum flow and natural runoff in each scheme group are small, while the difference between maximum flow and natural runoff is large.

(3) The occurrence time of annual extreme flow

Compared with natural runoff process before reservoir built, occurrence time of minimum flow of each scheme after reservoir built is earlier, and middle changes occurred. Maximum flow occurrence time of scheme after being built has less different, and degree of hydrological change is slight.

(4) High and low flow indicators

It can be observed in Fig.10 that occurrence time of low flow varies with different schemes, but average duration of low flow increases significantly. Occurrence frequency of high flow showed a significant decreasing trend, while duration of high flow showed an increasing tendency.

(5) Change rate and frequency of water flow conditions 
The flow change rate, frequency change process, and hydrological change degree of different schemes are shown in Fig.11. Compared with the natural state before reservoir built, average increase rate and average decrease rate of the flow after built of the reservoir are significantly reduced. Degree of change in hydrological indicators except for the middle change in Scheme 2, all other schemes are highly changed.

\subsubsection{Overall change}

Changes of 33 hydrological indicators of each scheme are summarized as showed in Table 4. It seems that:

(1) The built of reservoir causes hydrological indicator of all schemes to change to varying degrees except the number of flows breaking days. It can be found that the variation process of hydrological indicators in different ecological flow schemes is quite different by analyzing variation characteristics of 33 indicators in 7 schemes. Changing trends of hydrological indicators are inconsistent, indicating that different ecological flow processes are affected by reservoir operation methods.

(2) The high flow indicators (1-day, 3-day, 7-day, 30-day and 90-day), average flow increase rate, average flow decrease rate, and reversal times of Schemes 1 7 all change in middle or high degree, which indicates that different ecological flow schemes may face certain challenges in high flow regulation and flow change rate regulation.

Statistics the number of changes in hydrological indicator of different schemes and calculate overall change degree of hydrological indicator of each scheme, as shown in Table 5 and Fig.12. It can be seen from that the overall hydrological change degree of Scheme 2 Scheme 7 decreases in turn. The fluctuation range is between 0.53 and 0.66 , both of which are middle degree changes. 


\subsection{Results analysis of ecological flow scheme}

Ecological flow of Scheme 2- Scheme 7 is substituted into MIKE BASIN model, and day runoff data from 1964 to 2013 are used as inflow runoff process. Average annual water supply, annual average power generation, and ecological water guarantee rate of reservoirs under each operation scheme are shown in Table 6.

It can be seen from Table 6 that in terms of annual water supply, the water supply guarantee rate of reservoirs in Scheme 2 Scheme 7 is reduced, and annual water supply is less than the designed water supply of 500 million $\mathrm{m} 3$. The chief reason is that the design water demand at the initial stage of the project is 500 million $\mathrm{m} 3$ per year, which is more stringent than the annual average of 500 million m3; However, except Scheme 4, the guaranteed rate of the water supply of all schemes is over 90\%, among which Scheme 2 has the highest guaranteed rate. The Scheme 4 has the lowest guarantee rate. In terms of average annual power generation, the multi-year average power generation of each scheme has decreased compared with the design value, and the power generation of each scheme fluctuates in the range of 119-129 million $\mathrm{kW} \cdot \mathrm{h}$. In terms of ecological water guarantee rate, Scheme 2 is the highest, and Scheme 4 is the lowest.

\subsection{Optimal selection of ecological flow schemes}

The results show that: presence a contradictory relationship between ecological operation considering hydrological conditions, power generation, and water supply. For example, power generation and water supply in Scheme 2 are the best in all schemes, but the degree of ecological change is the highest. The ecological change degree of Scheme 7 is the lowest, but the calculation result is not optimal. Therefore, it is necessary to comprehensively consider all influencing factors, evaluate and select reasonable schemes. This paper chooses the Analytic Hierarchy Process (AHP) to 
assess each scheme (Tharme et al, 2003; Deng et al., 2012). The overall objective and decision-making criteria of reservoir operation are essential reference conditions for establishing decision-making indexes. On this basis, reasonable evaluation indexes are chosen according to completeness, scientifically, operability, and independence of decision-making indexes. In the initial stage of the Hanjiang-to-Weihe inter-basin water transfer project, Sanhekou Reservoir mainly undertakes the task of relieving the pressure of production and living water in the Guanzhong area and undertakes the task of power generation and downstream ecological water use. Scheme 2 Scheme 7 decreases the degree of hydrological change under the slightest damage to water supply efficiency. Therefore, this paper constructs evaluation indexes with three aspects of water supply, power generation, and ecology. In terms of water supply: the average annual water supply is $\mathrm{C} 1$, water supply guarantee rate is $\mathrm{C} 2$; in terms of power generation, the annual power generation is set as $\mathrm{C} 3$; in terms of ecology, the guaranteed rate of ecological water use is set as $\mathrm{C} 4$, and overall change degree of hydrology is set as C5.

(1) Constructing hierarchical judgment matrix

According to the number 1-9 as index scale (Deng et al, 2012), the target two groups are compared to construct a pair of comparison matrix A:

$$
A=\left[\begin{array}{cccccc} 
& C_{1} & C_{2} & C_{3} & C_{4} & C_{5} \\
C_{1} & 1 & 1 / 2 & 7 & 1 / 4 & 1 / 2 \\
C_{2} & 2 & 1 & 5 & 1 / 3 & 1 / 2 \\
C_{3} & 1 / 7 & 1 / 5 & 1 & 1 / 7 & 1 / 8 \\
C_{4} & 4 & 3 & 7 & 1 & 3 \\
C_{5} & 2 & 2 & 8 & 1 / 3 & 1
\end{array}\right]
$$

(2) Consistency testing

Maximum eigenvalue of the matrix is:

$$
\lambda_{\text {max }}=5.08
$$




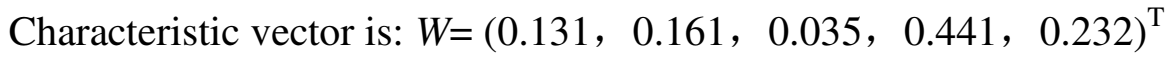

The consistency index of matrix A is calculated as follows:

$$
C I=\frac{\lambda_{\max }-n}{n-1}=\frac{5.08-5}{5-1}=0.021
$$

Query random consistency table to obtain $R I=1.12$, to further calculate consistency ratio.CR as following:

$$
C R=\frac{C I}{R I}=\frac{0.025}{0.12}=0.019<0.1
$$

After calculated from above formula: $C R<0.1$. It shows that consistency test is satisfied and consistency of judgment matrix is reasonable.

According to the index weight and normalization matrix, calculation results of each scheme are as follows:

$$
\mathrm{W}=(0.502,0.490,0.484,0.505,0.511,0.509)^{\mathrm{T}}
$$

The order of priority is: Scheme $6>$ Scheme $7>$ Scheme $5>$ Scheme $2>$ Scheme $3>$ Scheme 4 , so this paper-chase Scheme 6 as the preferred scheme.

It can be seen from above table that in recommended scheme 6, water supply and power generation benefits of the hydropower station have little influence. The hydrological change degree is reduced from high change $(72.91 \%)$ of the current operation scheme to middle change $(56.63 \%)$, and hydrological change degree is reduced by $16.28 \%$. Ecological water demand of Scheme 6 is shown in Fig.13, and corresponding reservoir multi-year operation process is shown in Fig.14.

Even if hydrological change degree lower to middle change, water supply guarantee rate and power generation still cannot reach the design values compared with those before reservoir built. The average value of the flow series decreases significantly, and the flow period shortens, which affects life rhythm of aquatic animals in the river. After built of the reservoir, flow dispersion degree 
increases, and the number of small flow events increases, so it is necessary to take action to protect it.

\subsection{Ecological flow safeguard measures}

It can be seen from above results that built of the reservoir has already affected ecological function of downstream river, so it is necessary to take engineering and non-engineering measures to protect downstream ecology.

\subsubsection{Engineering measures}

(1) Ecological operation, taking ecological factors into account in reservoir operation, can reduce the impact of reservoir operation on river ecological environment. Optimally adjust water quantity without changing total water volume of the basin, and reduce interference and stress of human activities on the river. More ecological flow can be obtained by changing operation mode of the reservoir.

(2) Sanhekou Reservoir is a water supply type reservoir. Damming and water diversion is fundamental reason for reduction of ecological water use. Water loss in water conveyance tunnel of Hanjiang-to-Weihe River diversion project is very large. So, optimizing water supply tunnel facilities, making technological innovations, and improving water supply efficiency to reduce water loss are effective measures to ensure ecological water use of rivers.

\subsubsection{Non-engineering measures}

(1) It is urgent to create and improve relevant laws and regulations to provide the basis and guidance for river ecological flow protection to solve the problem of weak environmental protection awareness of water users. In practical work, it is necessary to continue to improve relevant laws and regulations and establish an investment system for ecological flow protection funds. 
(2) It is necessary to increase the investment of manpower and capital in ecological environment protection and built to ensure that the Sanhekou water conservancy project can meet the ecological flow demand of downstream river for a long time. It mainly includes the division and protection of water sources, comprehensive treatment of pollution sources, strengthening the patrol inspection of water sources, and popularizing the concept of ecological environmental protection through television, the Internet, and other media.

(3) To ensure that Sanhekou water conservancy project can protect overall interests of whole basin, development of industry and agriculture in the middle-upper reaches of Ziwu River is limited, resulting in economic backwardness. River basin ecological compensation mechanism should be built to speed up social, economic, and environmentally sustainable development of whole river basin and improve enthusiasm of regional management departments in ecological flow protection.

(4) The built of monitoring and early warning mechanism for the discharge of Sanhekou Reservoir mainly includes setting monitoring sections, improving the layout of hydrological monitoring station network, and determining early warning level system of ecological flow and early warning release process. Using information technology to set up a basin early warning response platform to comprehensively improve ecological flow monitoring and early warning mechanism of the basin.

(5) Set up a comprehensive management system and strengthen monitoring and supervision; construct and improve the law enforcement mechanism; build river ecological flow law enforcement supervision consultation system and rapid response mechanism. Severely fight against violations of laws and regulations that destroy the ecological environment of rivers and occupy the ecological water of rivers. Set up an inspection system for key sections, and conduct regular inspections and irregular spot checks. Focus on strengthening inspections around key sections and ecologically 
sensitive areas; strengthen the ecological safety supervision of drinking water sources, and strengthen on-site law enforcement.

\section{Conclusions}

(1) The reservoir operation model establishes based on MIKE BASIN and verified rationality of the model by comparison with design water supply, ecological water quantity, and water level change process. On this basis, river flow process is simulated.

(2) The variation range method (RVA) is used to calculate change degree of 33 hydrological indicators after built of the reservoir. The results show that operation of the reservoir has a great impact on hydrological situation of the river channel, and the overall hydrological change degree is $72.91 \%$, which belongs to a high degree of change.

(3) Analysis of shortcomings of the current regulation scheme, a variety of ecological flow schemes proposed from perspective of the annual hydrological situation and inter annual wet and dry changes. Evaluate scheme set based on the analytic hierarchy process, select and recommend ecological flow scheme 6. Put forward reservoir operation mode under Scheme 6, research results provide technical support for how to reduce the influence of reservoir scheduling.

In this paper, hydrological response relationship of the initial operation of Hanjiang-to-Weihe river diversion project is studied, and some achievements are obtained. However, due to high uncertainty of hydrological response, and limited to the author's research level and limitations of regional data, there are some shortcomings in this paper, which need further study and improvement.

\section{Credit authorship contribution statement}


Tao Bai: Term, Software, Resources, Writing - Original Draft, Visualization, Project administration, Funding acquisition. Xian-ge Sun: Investigation, Data Curation, Writing - Review \& Editing. Jian Wei: Validation, Formal analysis. Lianzhou Wu: Conceptualization, Supervision.

\section{Acknowledgement}

This research was funded by the following projects:

National Natural Science Foundation of China (Grant No.52179025)

National Natural Science Foundation of China (Grant No. 51879213)

Project funded by China Postdoctoral Science Foundation (2019T120933)

Basic Research Plan of Natural Science of Shaanxi Province (2019JLM-52)

Planning project of science and technology of water resources of Shaanxi (2017slkj-16)

\section{References}

Al-Faraj F.A.M, Scholz.M. Assessment of temporal hydrologic anomalies coupled with drought impact for a transboundary river flow regime: The Diyala watershed case study[J]. Journal of Hydrology, 2014, 517: 64-73. https://doi.org/10.1016/j.jhydrol.2014.05.021

Ashraf F.B, Torabi H.A, Marttila.H, et al. Assessing impacts of climate change and river reg ulation on flow regimes in cold climate: A study of a pristine and a regulated river in the sub-arctic setting of Northern Europe[J]. Journal of Hydrology, 2016, 542: 410-422. https://doi.org/10.1016/j.jhydrol.2016.09.016

Ban, X, Shi, C.W, Guo, H, et al. Impact of climate change and water conservancy projects on the hydrological situation downstream of Danjiangkou Dam [J]. Advances in Science and Technology of Water Resources, 2020,40(04):1-7. DOI:10.3880/j.issn.1006 7647.2020.04.001 
Bernard Mérona, Régis Vigouroux, Tejerina-Garro F L. Alteration of Fish Diversity Downstream from Petit-Saut Dam in French Guiana. Implication of Ecological Strategies of Fish Species[J]. Hydrobiology, 2005, 551(1): 33-47. https://doi.org/10.1007/s10750-005-4448-z

Chang, F.X, Chen, J, Zhang, Z.Y. Study on eco-environmental water demand in the upper Hanjiang River [J]. Journal of Yangtze River Scientific Research Institute, 2007, (06):18-21.

Chen, W.D, Bao, W.M, Zhang Q, et al. Analysis of the impact of Jinjiang reservoir on downstream runoff based on IHA [J]. Journal of China Three Gorges University(Natural Sciences), 2015, (37):27. DOI:10. 13393/j.cnki.issn.1672-948x.2015.03.006

Chen, X, Gu, S.X, Xie, B, et al. Application of MIKE BASIN in Water Resources Demonstration [J]. China Rural Water and Hydropower, 2009, (10):8-11.

Costigan, K.H, Daniels, M.D. Damming the prairie: Human alteration of Great Plains river regimes[J]. Journal of Hydrology, 2012, 444-445. https://doi.org/10.1016/j.jhydrol.2012.04.008

Cui, B.L.; Chang, X.L.; Shi, W.Y. Abrupt Changes of Runoff and Sediment Load in the Lower Reaches of the Yellow River[J]. Water Resources. 2014, 41, 252-260. DOI: $10.1134 / \mathrm{S} 009780781403004 \mathrm{X}$

Deng, X, Li, J.M, Zeng, H.J, et al. Analytic Hierarchy Process Weight Calculation Method Analysis and Application Research [J]. Journal of Mathematics in Practice and Theory, 2012, 42 (07):93-100.

Gao, Y, Xie, Y.H, Zou, D.S. Hydrological changes of the three Jingjiang Estuary before and after the operation of the Three Gorges Project [J]. Resources and Environment in the Yangtze Basin, 2020, 29 (02):479-487. DOI: 10. 11870/cjlyzyyhj202002021

Guo, W.X, Li, Y, Wang, H.X, Zha H.F. Based on the IHA-RVA method, the ecological hydr 
ological situation evaluation of the downstream rivers of the Three Gorges Reservoir [J]. Resources and Environment in the Yangtze Basin, 2018, 27 (09):2014-2021. DOI: 10. 1 1870/cjlyzyyhj201809012

Han, T.G. Problems and countermeasures for the conservation of aquatic biological resources in Xiaolangdi Reservoir[J]. Henan Fisheries. 2014, 98, 11-12+24.

Hassaballah, K, Jonoski, A, Popescu, I, et al. Model-Based Optimization of Downstream Impact during Filling of a New Reservoir: Case Study of Mandaya/Roseires Reservoirs on the Blue Nile River[J]. Water Resources Management, 2012, 26(2):273-293. https://doi.org/10.1007/s11269-011-9917-8

Huang, H.K. Study on the Comprehensive Influence of Feilaixia Hydraulic Complex on Beijiang River [J]. Guangdong Water Resources and Hydropower, 2014, (07):91-93+100.

$\underline{\text { Ibraim, F-C, }} \underline{\text { Olavo,P, }} \underline{\text { Pierre,G, }}$, et al. Effects of a Diversion Hydropower Facility on the Hydrological Regime of the Correntes River, a Tributary to the Pantanal floodplain, Brazil[J]. Journal of Hydrology, 2015, 531(3): 810-820. https://doi.org/10.1016/j.jhydrol.2015.10.045

Jha, M.K.; Gupta, A.D. Application of MIKE BASIN for water management strategies in a watershed[J]. Water International, 2003, 28(1): 27-35. https://doi.org/10.1080/02508060308 691662

Kang, L, Huang, Y.Y, Yang, Z.X, et al. Reservoir ecological operation model and its application [J]. $\begin{array}{lllll}\text { Journal } & \text { of } \quad \text { Hydraulic } \quad \text { Engineering, } & 2010, & 41 & \text { (02):134-141. }\end{array}$ DOI:10.13243/j.cnki.slxb.2010.02.008

Li, P . Research on the water resources allocation scheme above Harbin section of Songhua River Basin based on MIKE BASIN [D]. Jilin:Jilin University, 2013. 
Li, Z.Y, Liu, D.F, Huang, Q, et al. Research on the ecological flow of the Hanjiang River based on various hydrological methods [J]. Journal of North China University of Water Resources and Electric Power(Natural Science Edition), 2017, 38 (01):8-12. DOI:10.3969/j.issn.1002 5634.2017 .01 .002

Lu, S.C. Research on water resources management model of Shiyang River Basin based on MIKE BASIN [D] Beijing: Tsinghua University, 2016.

Mccully, P. Silenced rivers: The ecology and politics of large dams [M]. London: Zed Books Ltd, 2001

Meng, F.C, Li, Q.J, Shen, C.S, et al. Water resources allocation in reclaimed water irrigation districts based on MIKE Basin model [J]. Journal of Irrigation and Drainage, 2014, 33 (6):10-13. DOI:10.13522/j.cnki.ggps.2014.06.003

Natália, C.L.S, Emili, G.B, Juliana, D.D, et al. Cumulative ecological effects of a Neotropica 1 reservoir cascade across multiple assemblages[J]. Hydrobiologia, 2018, 819(1): 77-91. h ttps://doi.org/10.1007/s10750-018-3630-z

Oscar, B, Daniel, B, Francisco, M. C, et al. Effects of flow regime alteration on fluvial habi tats and riparian quality in a semiarid Mediterranean Basin[J]. Ecological Indicators, 201 3, 30: 52-64. https://doi.org/10.1016/j.ecolind.2013.01.042

Qi, L.L, Zhang, B, Lai, Q.F, et al. Comparative analysis of water resources rational allocation schemes based on MIKE BASIN — taking Changji Economic Circle as an example [J]. Water Resources and Hydropower Engineering, 2018, 49 (05):16-24. Doi: 10. 13928 /j. cnki. wrahe. 2018. 05.003

Richter, B. D, Baumgartner, J V, Powell, J, et al. A Method for Assessing Hydrologic Altera 
tion within Ecosystems[J]. Society for Conservation Biology, 1996, 10(4): 1163-1174. htt ps://doi.org/10.1046/j.1523-1739.1996.10041163.x

Richter, B D, Baumgartner, J V, Wigington, R, et al. How Much Water Does a River Need ?[J] Freshwater Biology, 1997, 37(1): 231-249. https://doi.org/10.1046/j.1365-2427.1997.00153.x

Swapan, T, Swades, P. Effects of damming on the hydrological regime of Punarbhaba river basin wetlands[J]. Ecological Engineering,2019,135:61-74. Effects of damming on the hydrological regime of Punarbhaba river basin wetlands

Tharme, R E. A global perspective on environmental flow assessment: emerging trends in th e development and application of environmental flow methodologies for rivers[J]. Wiley Online Library ,2003, 19(5-6): 397-441. https://doi.org/10.1002/rra.736

Xu, Z.X, Dong, Z.C, Zhou, J.K, et al. Montana method for ecological water demand calculation and its application [J]. Water Resources and Hydropower Engineering, 2003, (11):15-17. DOI: 10. 13928 /j.cnki.wrahe.2003. 11. 005

Yang, J, Wang, N, Chen, Y. Effect of cascade development of river hydropower resources on the ecological environment [J] Journal of Water Resources and Water Engineering, 2013,24 (04):58-62.

Zhang, Y, Wang, D.M, Wang, X.Q, et al. The impact of reservoir built on river hydrology i n the Taizi River Basin [J]. Acta Scientiae Circumstantiae, 2012, 25 (04):363-371. DOI: 10.13671/j.hjkxxb.2012.12.030 
Figures

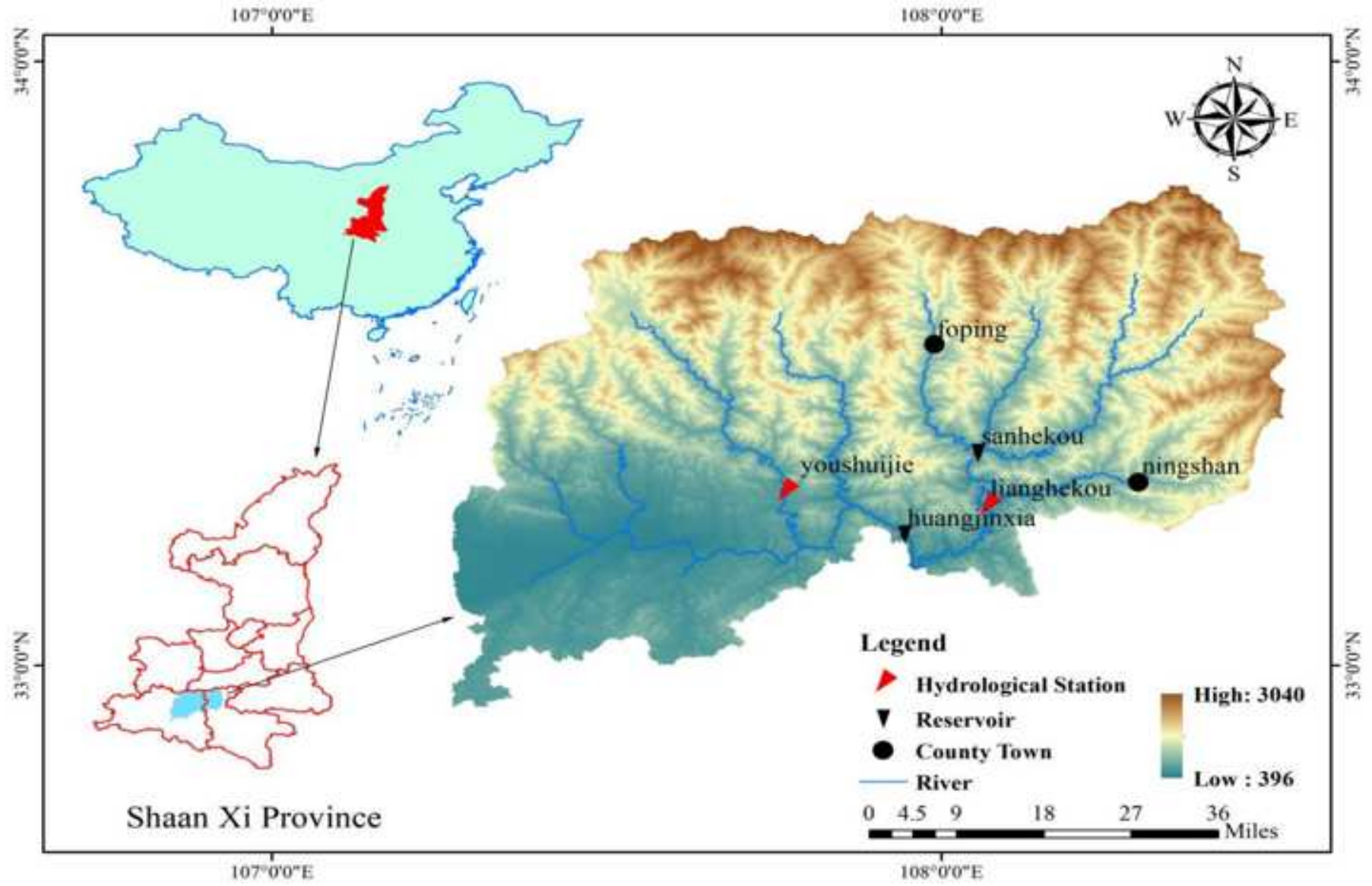

Figure 1

The distribution diagram of reservoirs and hydrological stations in the water diversion area of Hanjiang to Weihe inter-basin water transfer project

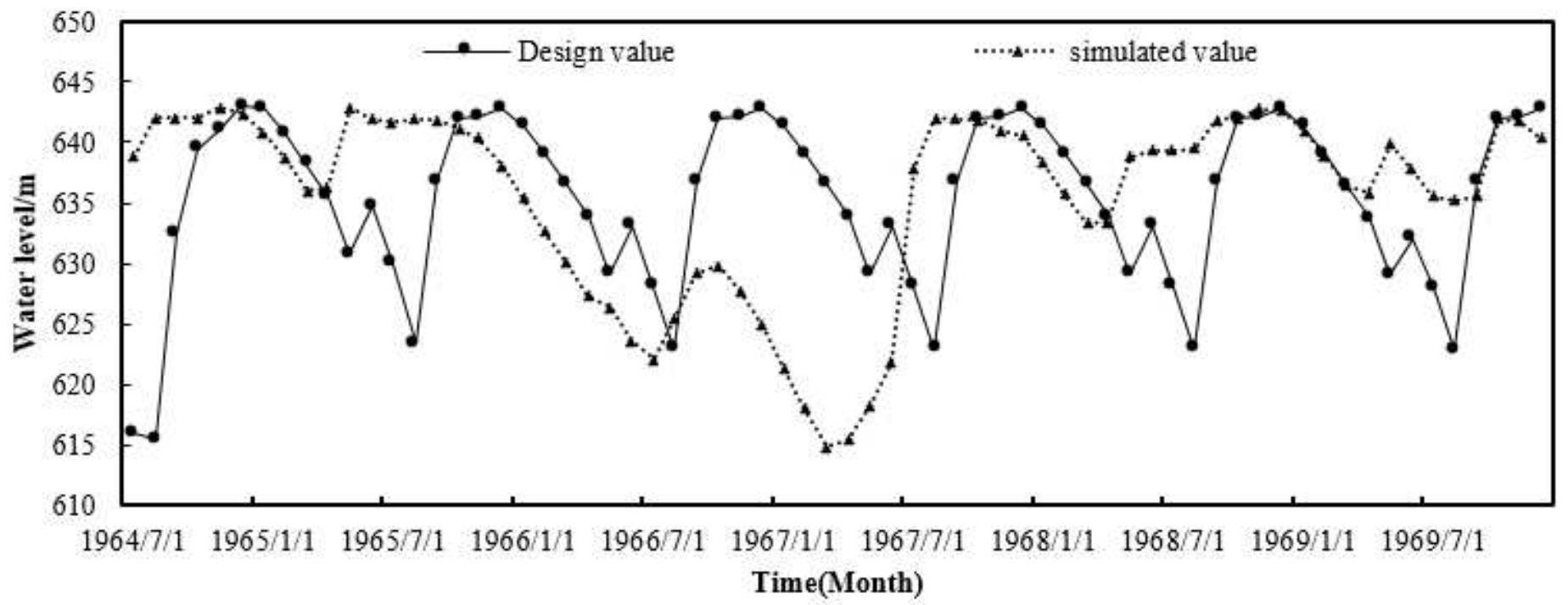


Figure 2

Sanhekou Reservoir simulation water level and design water level process line

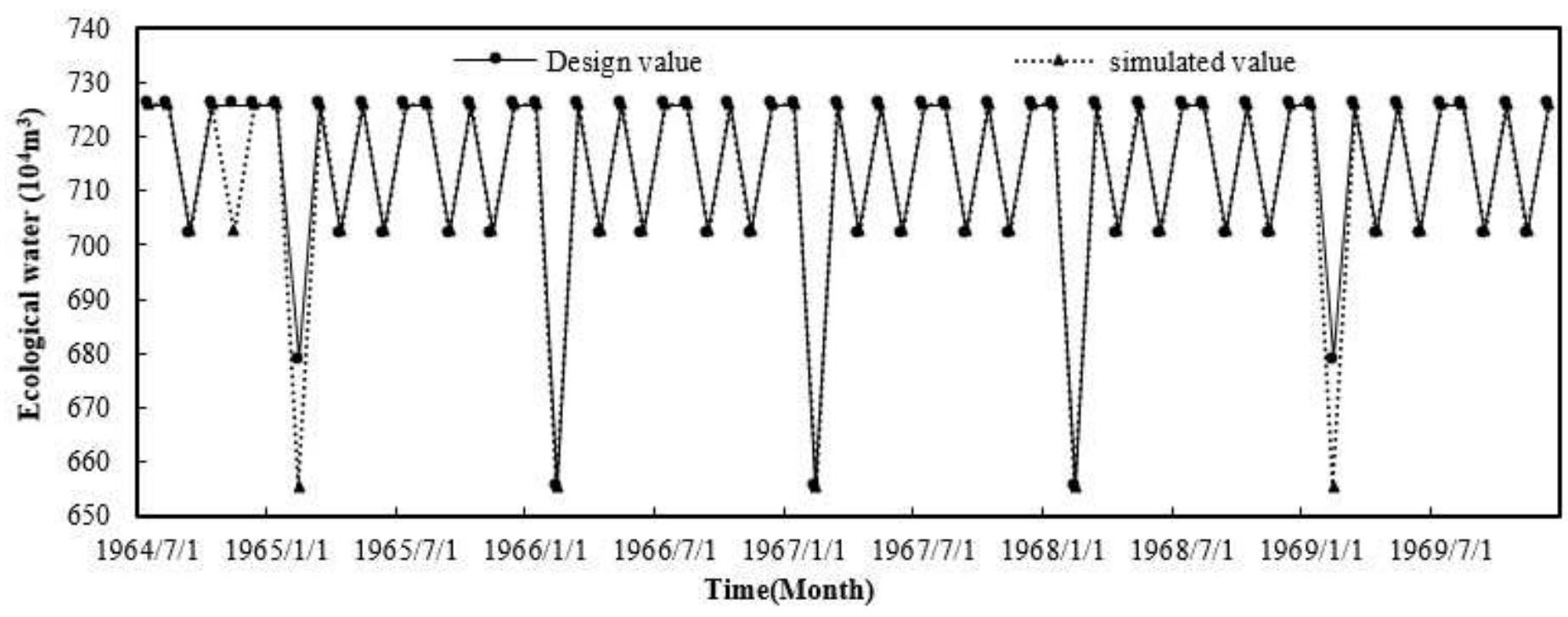

Figure 3

Sanhekou Reservoir simulation ecological water quantity and design ecological water quantity process line

Figure 4

Sanhekou Reservoir simulation water supply and design water supply process line

Figure 5

Sanhekou Reservoir inflow runoff and outflow runoff

Figure 6

(a) Distribution of hydrological indicator change degree after Sanhekou Reservoir operation

(b) Distribution of hydrological indicator change degree after Sanhekou Reservoir operation 


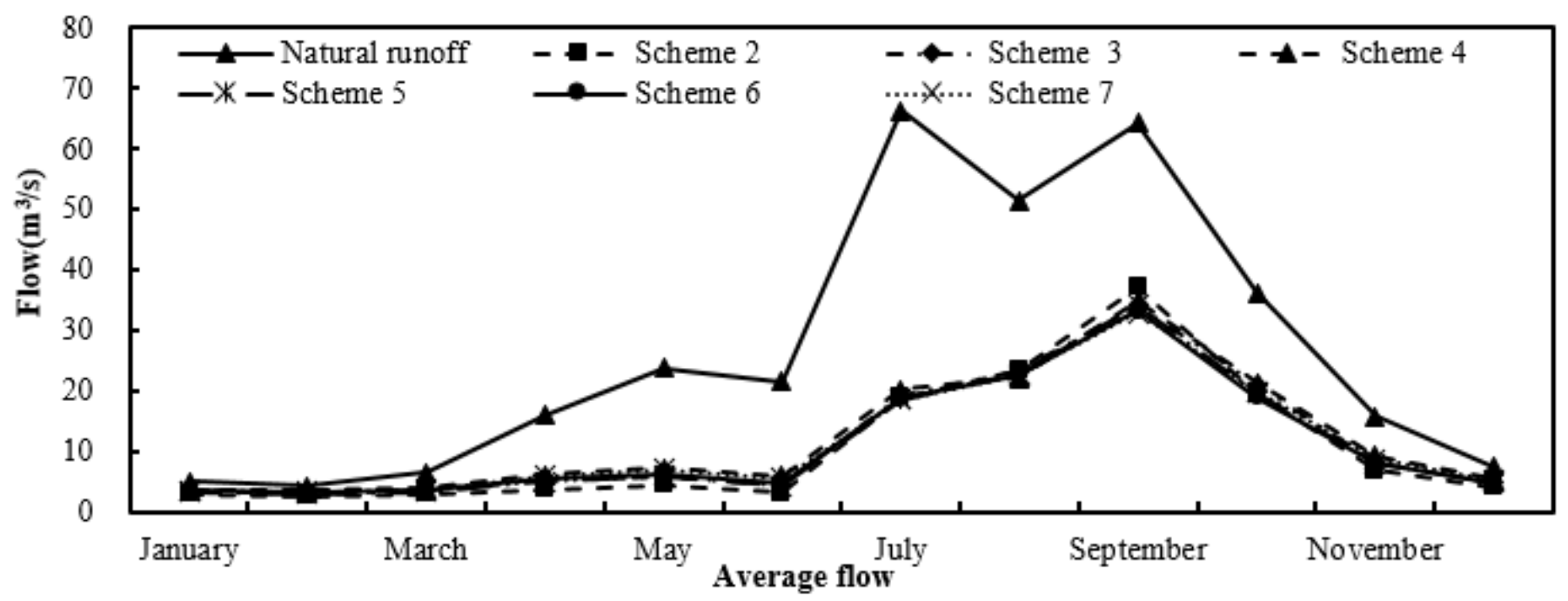

Figure 7

The change process of monthly average traffic under different schemes after Sanhekou Reservoir operation

\section{Figure 8}

Minimum flow change process under different schemes after Sanhekou Reservoir operation

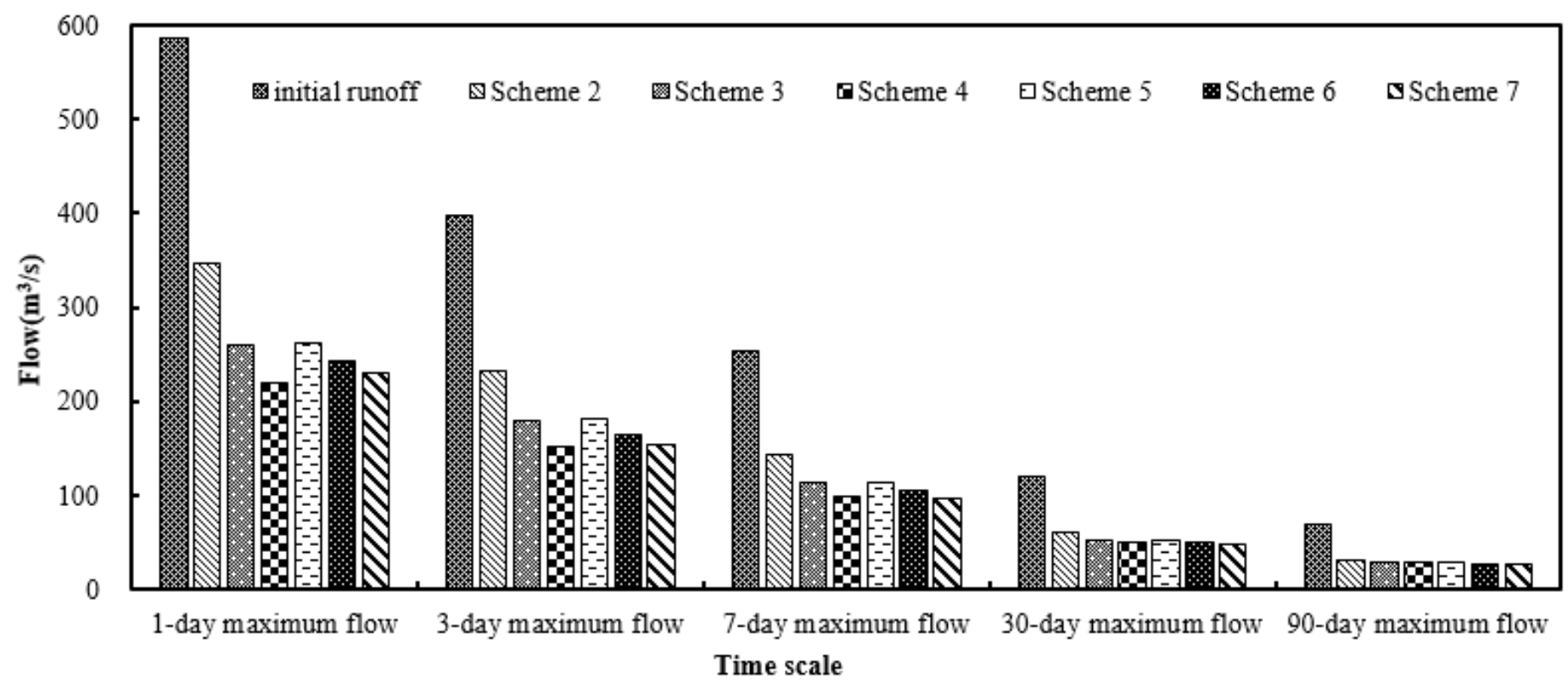

Figure 9 
Figure 10

Pulse flow indicators under different schemes after Sanhekou Reservoir operation

Figure 11

Flow change rate under different schemes after Sanhekou Reservoir operation

Figure 12

IHA indicators change degree under different schemes after Sanhekou Reservoir operation

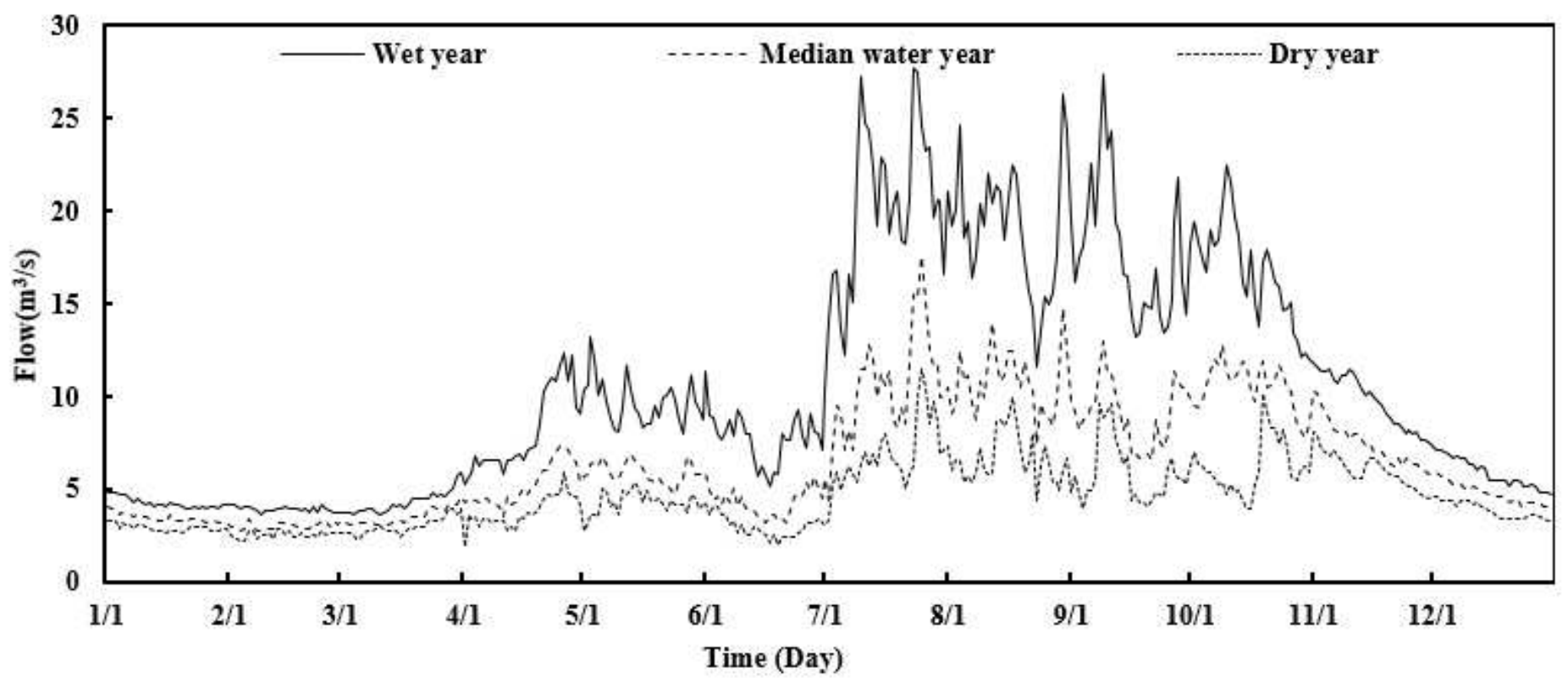

Figure 13

Ecological flow process of Scheme 6

Figure 14

Multi-year reservoir operation process of Scheme 6 